University of Wollongong

Research Online

Faculty of Engineering and Information

Faculty of Engineering and Information

Sciences - Papers: Part B

Sciences

2018

Experimental Investigation and Assessment of Internal Stability of Granular Filters under One-Dimensional Static and Cyclic Loading

Jahanzaib Israr

University of Wollongong, jisrar@uow.edu.au

Jehangir Israr

Water and Sanitation Agency

Follow this and additional works at: https://ro.uow.edu.au/eispapers1

Part of the Engineering Commons, and the Science and Technology Studies Commons

Research Online is the open access institutional repository for the University of Wollongong. For further information contact the UOW Library: research-pubs@uow.edu.au 


\title{
Experimental Investigation and Assessment of Internal Stability of Granular Filters under One-Dimensional Static and Cyclic Loading
}

\begin{abstract}
Internal instability occurs when the finer fraction of a filter escapes with the infiltrates, causing permanent changes to its particle size distribution and rendering it ineffective. Thus far, numerous criteria based on particle and constriction size distributions have been proposed to assess the potential of internal instability. This paper reports the results of pressure gradient controlled hydraulic tests performed on granular soils including silt-sand-gravel, sand, and sand-gravel mixtures with their uniformity coefficients ranging from 1 to 304 and compacted at varying relative densities between 0 and $100 \%$. Select dense samples were then subjected to a series of hydraulic tests under static loading up to $100 \mathrm{kPa}$ and cyclic loading up to $30 \mathrm{~Hz}$, simulating subballast filtration under heavy-haul freight trains with speeds as high as $210 \mathrm{~km} / \mathrm{h}$. The analysis revealed that the agitation and pore pressure development under cyclic loading promotes premature suffusion, thereby making it the worst case of filtration. An objective evaluation of some of the existing criteria led to a more realistic interpretation of experimental results based on a modified technique that accurately assessed the internal stability of soils under cyclic loading. Results of internal stability assessments from existing geometrical criteria were then compared with those from the proposed technique, which showed enhanced success, thereby contributing to increased confidence in the practical design of granular filters under cyclic conditions.

\section{Disciplines}

Engineering | Science and Technology Studies

\section{Publication Details}

Israr, J. \& Israr, J. (2018). Experimental Investigation and Assessment of Internal Stability of Granular Filters under One-Dimensional Static and Cyclic Loading. Geotechnical Testing Journal, 41 (1), 103-116.
\end{abstract}


Manuscript received January 18 , 2017; accepted for publication June 22, 2017; published online December 11, 2017.

1 University of Engineering \& Technology, Lahore, Pakistan; and University of Wollongong, Wollongong City, NSW 2522, Australia (Corresponding author), e-mail: jisrar@uow.edu.au, (1) https://orcid.org/0000-00023927-4995

2 Water and Sanitation Agency (WASA), Lahore, Pakistan
Jahanzaib Israr ${ }^{1}$ and Jehangir Israr $^{2}$

\section{Experimental Investigation and Assessment of Internal Stability of Granular Filters under One-Dimensional Static and Cyclic Loading}

\section{Reference}

Israr, J. and Israr, J., "Experimental Investigation and Assessment of Internal Stability of Granular Filters under One-Dimensional Static and Cyclic Loading," Geotechnical Testing Journal, Vol. 41, No. 1, 2018, pp. 103-116, https:// doi.org/10.1520/GTJ20170027. ISSN 0149-6115

\section{ABSTRACT}

Internal instability occurs when the finer fraction of a filter escapes with the infiltrates, causing permanent changes to its particle size distribution and rendering it ineffective. Thus far, numerous criteria based on particle and constriction size distributions have been proposed to assess the potential of internal instability. This paper reports the results of pressure gradient controlled hydraulic tests performed on granular soils including silt-sand-gravel, sand, and sand-gravel mixtures with their uniformity coefficients ranging from 1 to 304 and compacted at varying relative densities between 0 and $100 \%$. Select dense samples were then subjected to a series of hydraulic tests under static loading up to $100 \mathrm{kPa}$ and cyclic loading up to $30 \mathrm{~Hz}$, simulating subballast filtration under heavy-haul freight trains with speeds as high as $210 \mathrm{~km} / \mathrm{h}$. The analysis revealed that the agitation and pore pressure development under cyclic loading promotes premature suffusion, thereby making it the worst case of filtration. An objective evaluation of some of the existing criteria led to a more realistic interpretation of experimental results based on a modified technique that accurately assessed the internal stability of soils under cyclic loading. Results of internal stability assessments from existing geometrical criteria were then compared with those from the proposed technique, which showed enhanced success, thereby contributing to increased confidence in the practical design of granular filters under cyclic conditions.

\section{Keywords}

granular filters, internal stability, static, cyclic loading, frequency

\section{Nomenclature}

$\gamma_{s}$ and $\gamma_{w}=$ unit weight of soil and water, respectively;

$\sigma_{v t}^{\prime}$ and $\sigma_{v, \text { mean }}^{\prime}=$ vertical and mean effective stresses, respectively $(\mathrm{kPa})$;

$\mathrm{ADR}=$ amplitude domain reflectometry;

$C_{u}=$ coefficient of uniformity; 


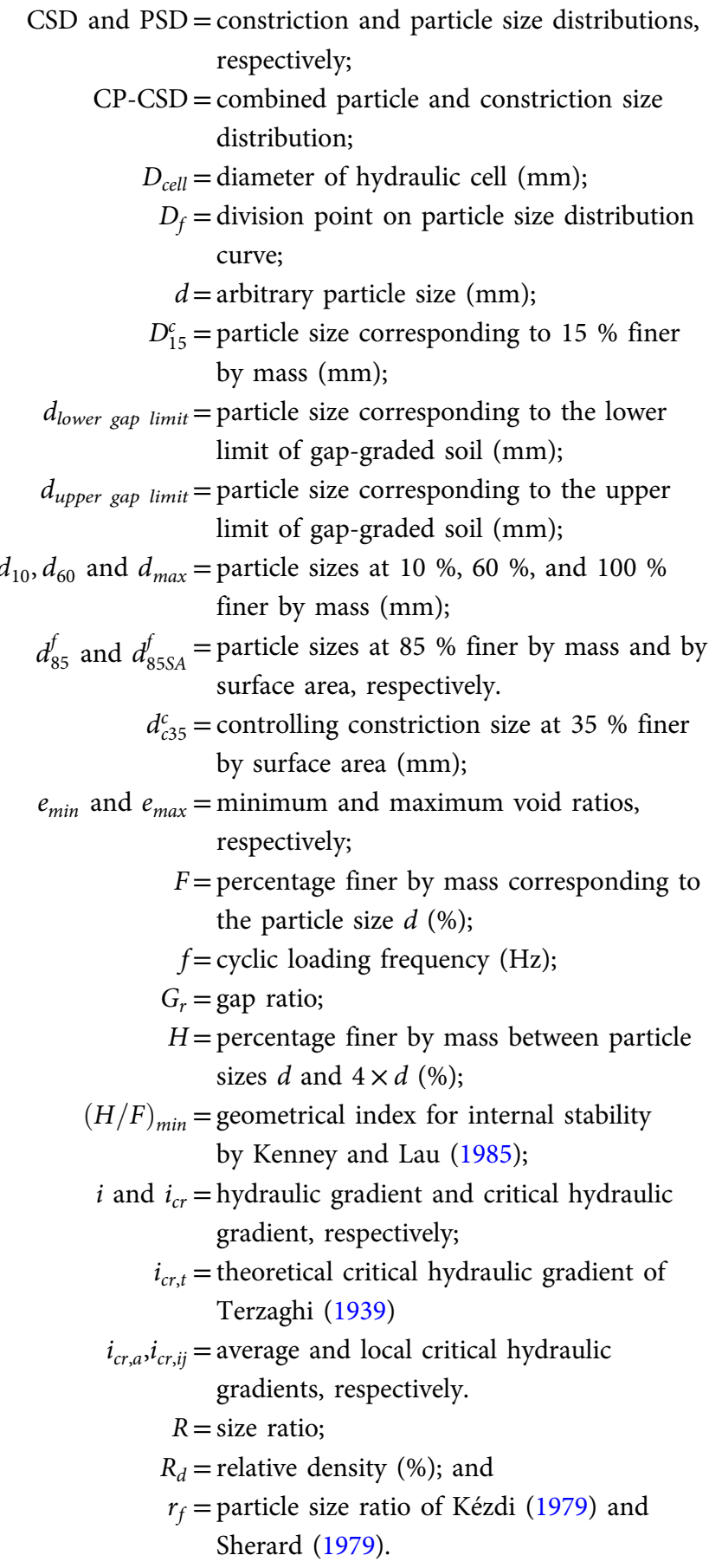

\section{Introduction}

Granular soils have implications as filter and drainage layers in numerous civil infrastructures due to their excellent drainage and load carrying capacities. As filters, they are expected to arrest the eroding base particles without clogging to avoid the development of excess pore pressure in earth structures. While doing so, they should not exhibit washout of their finer fraction (internal instability) due to significant seepage forces and disturbance caused by the severe mechanical loads, e.g., dynamic loads in railway substructures. The occurrence of internal instability could significantly affect geomechanical characteristics of granular filters, consequently rendering them ineffective in retaining the protected base soil and eventually endangering structural stability (Israr and Indraratna 2017; Xiao and Shwiyhat 2012; Smith and Bhatia 2010; Fourie, Copeland, and Barrett 1994).

Internal instability occurs in nonuniform soils possessing a bimodal structure that consists of a stable coarser fraction and an erodible finer fraction (Skempton and Brogan 1994). In such soils, the finer fraction resides inside the pore spaces of stable fabric and can only erode out if the constriction network formed by the coarser fraction cannot retain the finer fraction. This is known as the geometrical requirement for the occurrence of internal instability (Kenney and Lau 1985). Once seepage neutralizes the inertial forces on the fine particles after the geometrical requirement is met, the internal erosion begins, and this point is termed as the onset of internal instability (Israr, Indraratna, and Rujikiatkamjorn 2016). At such onset, the eroding fines carry negligible effective stress compared to the stable coarse particles that sustainably carry and transfer the major proportion ( $\mathrm{Li}$ and Fannin 2008; Israr and Indraratna 2017). Recently, Trani and Indraratna (2010) reported that the severity of hydromechanical conditions such as large hydraulic gradients accompanied with cyclic loading could trigger instability even in geometrically stable soils. Thus far, numerous empirical criteria have been proposed based on observations from static filtration tests to assess the internal stability of soils, generally ignoring the effects of soil compaction, cyclic loading, and applied hydraulic gradients.

This current study aimed to examine some of the physical and hydraulic factors affecting the internal stability of soils. Results from a large experimental program divided into 3 phases with 61 hydraulic tests conducted on 10 granular soils under static and cyclic loading have been reported. The first phase comprised 24 tests to assess the role of particle size distribution (PSD) and relative density $\left(R_{d}\right)$ of soils. The later phases have been designed to simulate the practical field conditions. For instance, phase 2 simulated the downstream filters in dams, whereas phase 3 modelled the subballast filters in a railway substructure experiencing a cyclic heavy haul freight load. During phase 2, the effects of varying the effective stress magnitude on internal stability potential and internal erosion were evaluated through 15 additional hydraulic tests. Phase 3 examined the effects of cyclic loading frequency on the occurrence of internal instability through 22 additional tests. Furthermore, the test results of phases 2 and 3 have been compared to evaluate the effects of cyclic loading on the extent of internal erosion and specimen behavior. Nonetheless, the experimental results of this study could be used to evaluate and improve upon one of the well-accepted geometrical criteria based on constriction size distribution (CSD). A summary of some of the well-accepted criteria is presented in the following section. 


\section{Existing Criteria for Internal Stability Assessments}

As a pioneer, USACE (1953) first examined the role of PSD in controlling the inherent or internal stability of soils. The amount of erodible finer fraction was deemed as the most critical factor, and empirical threshold values of finer fraction were proposed to control the occurrence of instability. Kézdi (1979) and Sherard (1979) applied Terzaghi's filter retention criterion to assess the internal instability potential of soils with some success. According to their criteria, a given PSD curve is divided into coarser and finer fractions. The division point $D_{f}$ on the curve is chosen repeatedly in search of the maximum value of $r_{f}$, which is the ratio between the controlling particle size of the coarser fraction $d_{15}^{c}$ and the characteristic size of the finer fraction $d_{85}^{f}$ (Skempton and Brogan 1994; Reddi 2003). A limiting value of $r_{f} \leq 4$ was proposed by Kézdi (1979), whereas a less conservative boundary of 5 was proposed for $r_{f}$ by Sherard (1979). The criterion of Kézdi (1979) was subsequently validated by others as an acceptable guide (Fannin and Moffat 2006).

Kenney and Lau (1985) experimentally evaluated the role of PSD of soils in greater detail under extreme hydraulic conditions and reported that the shapes and slopes of PSD curves controlled the potential of internal instability. Kenney and Lau (1985) assumed that an arbitrary particle size $d$ could erode through a constriction formed by particle size $4 \times d$ or larger. The PSD curve is repeatedly demarcated at a point corresponding to the particle size $d$ and the percentage finer by mass $F$; another point is determined at $4 \times d$, and $H$ is calculated as the percentage finer between particle sizes $d$ and $4 d$. The $(H / F)$ ratio is deduced every time, and a soil possessing $(H / F)_{\min } \geq 1$ is deemed internally unstable. Kenney and Lau (1985) and Indraratna, Israr, and Rujikiatkamjorn (2016) subsequently validated this criterion with large experimental datasets that showed a higher success rate than the criteria of Kézdi (1979) and Sherard (1979). Interestingly, Chapuis (1992) unified all these criteria in a single method, which is represented as a measure of the slope of the PSD curve.

Indraratna, Israr, and Rujikiatkamjorn (2015) evaluated the role of CSD of coarse fraction and PSD of finer fraction in tandem and proposed a combined particle and constriction size distribution (CP-CSD) approach to demarcate a clear boundary between internally stable and unstable soils. According to the CP-CSD method, the PSD curve of a given soil is demarcated at a point corresponding to a $(H / F)_{\min }$ value to obtain a coarser (filter) and a finer (base) fraction. As a next step, the CSD curve of the filter fraction at a given $R_{d}$ and the PSD curve of the base fraction are drawn using surface area methods. The controlling constriction size of the filter corresponding to $35 \%$ finer $\left(d_{c 35}^{c}\right)$ and the characteristic particle size of the base corresponding to
$85 \%$ finer by surface area $\left(d_{85 S A}^{f}\right)$ are determined. The criterion is given by the following (Indraratna, Israr, and Rujikiatkamjorn 2015):

$$
d_{c 35}^{c} / d_{85 S A}^{f} \leq 1
$$

A soil possessing $d_{c 35}^{c}>d_{85 S A}^{f}$ would be characterized as internally unstable. Indraratna, Israr, and Rujikiatkamjorn (2015) verified this approach with a large experimental dataset of 91 results obtained from their own laboratory results and those adopted from published literature. This method claimed $99 \%$ success in correctly assessing internal stability compared to the criteria of Kézdi (1979), Sherard (1979), and Kenney and Lau (1985), who achieved 60,60, and $85 \%$ success, respectively. Unlike traditional PSD-based geometrical methods, the CP-CSD criterion is sensitive to both PSD and $R_{d}$ of soil.

\section{Experimental Program}

\section{TEST MATERIAL}

The test material for the current study consisted of ten granular (cohesionless) soils including three uniform, two well-graded, three broadly graded, and two gap-graded soils, as shown in Fig. 1. Table 1 presents the physical characteristics of the soil gradations tested in this study, including uniformity coefficient $C_{u}$ $\left(=d_{60} / d_{10}\right)$, gap ratio $G_{r}\left(=d_{\text {upper gap limit }} / d_{\text {lower gap limit }}\right)$, and soil description. Notably, the selected soils generally plot within the typical subballast filter selection range in New South Wales, Australia (Israr 2016; Christie 2007).

FIG. 1 Soil gradations for current test specimens.

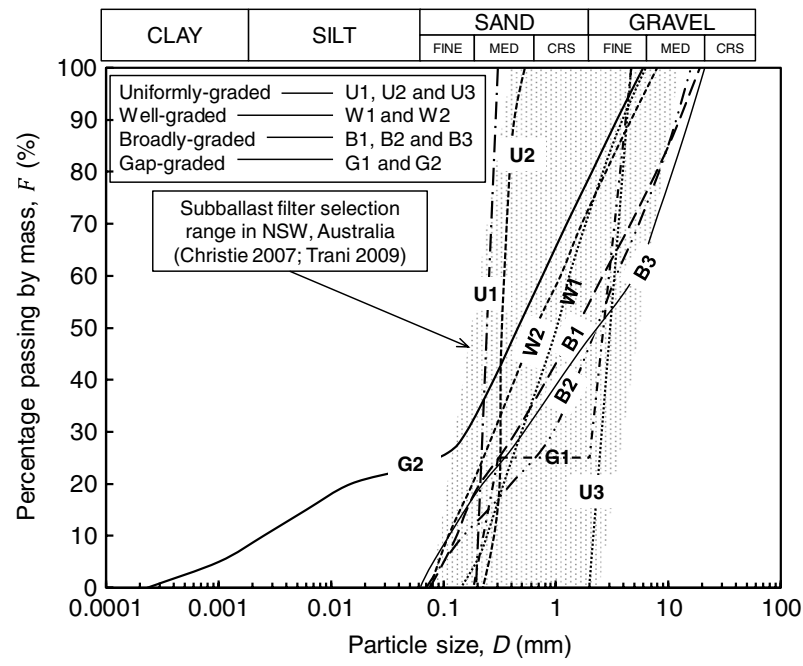


TABLE 1 Physical characteristics of current test soils.

\begin{tabular}{lcccc} 
Sample & & & \\
ID & $C_{u}$ & $G_{r}$ & $*(H / F)_{\min }$ & Soil Description \\
\hline U1 & 1 & - & - & Uniform medium \\
U2 & 1.2 & - & - & sand \\
U3 & 1.5 & - & - & Uniform fine gravel \\
W1 & 5 & - & 1.4 & Well-graded \\
W2 & 10 & - & 1.07 & gravelly sand \\
B1 & 20 & - & 0.73 & Broadly graded \\
B2 & 23 & - & 1.06 & gravelly sand \\
B3 & 40 & - & 0.7 & Gap-graded gravelly sand \\
G1 & 20 & 5 & - & Gap-graded silt-sand-gravel \\
G2 & 304 & 10 & - & mixture \\
& & & &
\end{tabular}

Note: $C_{u}, G_{r}$, and $(H / F)_{\min }$ represent coefficient of uniformity, gap ratio, and internal stability index of Kenney and Lau (1985), respectively.

${ }^{*}(H / F)_{\min }$ is infinite for uniform and zero for gap-graded soils.

\section{TEST SETUP AND APPARATUS}

Fig. 2 presents the schematic illustration of the setup and apparatus for this study. The test chamber consisted of a low friction polycarbon cell with an internal diameter of $240 \mathrm{~mm}$ and height of $200 \mathrm{~mm}$. To avoid the potential effects of boundary wall friction, i.e., preferential flow paths and excessive frictional resistance to erosion of fines, the hydraulic cell diameter $\left(D_{\text {cell }}\right)$ restricts the maximum particle size $\left(d_{\text {max }}\right)$ of testing material. For instance, the gradient ratio standard test method ASTM D5101, Standard Test Method for Measuring the Soil-Geotextile System Clogging Potential by the Gradient Ratio, requires $d_{\text {max }}$ to be less than $D_{\text {cell }} / 10$. According to Head (1982), the ratio $R$ ( $=D_{\text {cell }} / d_{\text {max }}$ ) should be at least 12 , while Kenney et al. (1985) used an apparatus with $R \geq 10$. In the past, most hydraulic testing was conducted using equipment with $4 \leq R \leq 7$, which was sufficient to avoid the boundary effects, and reported consistent results (e.g., see Fannin and Moffat 2006; Moffat, Fannin, and Garner 2011; Zou et al. 2013). The current apparatus was large enough to yield $R \geq 12$, which was deemed sufficient to avoid the effects of boundary and instrumentation on soil erosion plus the development of preferential flow paths. The seepage-induced variations in specimen porosity, head losses, and associated effective stress variations were captured using arrays of three amplitude domain reflectometry (ADR) probes, eight pore pressure transducers, and three load sensors probed at different depths, respectively (Fig. 2). The test specimens were placed inside the hydraulic cell over a wire mesh (opening $=80 \mu \mathrm{m}$ ) and then compacted to the target height. An electropneumatic pump connected to the bottom facilitated the application of inflow at predetermined hydraulic pressures. Further details on the apparatus' performance and test repeatability may be obtained from Israr, Indraratna, and Rujikiatkamjorn (2016).

\section{SPECIMEN PREPARATION AND TEST PROCEDURE}

The soils were mixed beforehand, and 200-mm-long specimens were compacted in five layers to the target relative density $\left(R_{d}\right)$ by
FIG. 2 Laboratory hydraulic test setup; (a) schematic illustration of test chamber, (b) illustration of top view of test chamber, and (c) actual hydraulic cell with soil specimen.
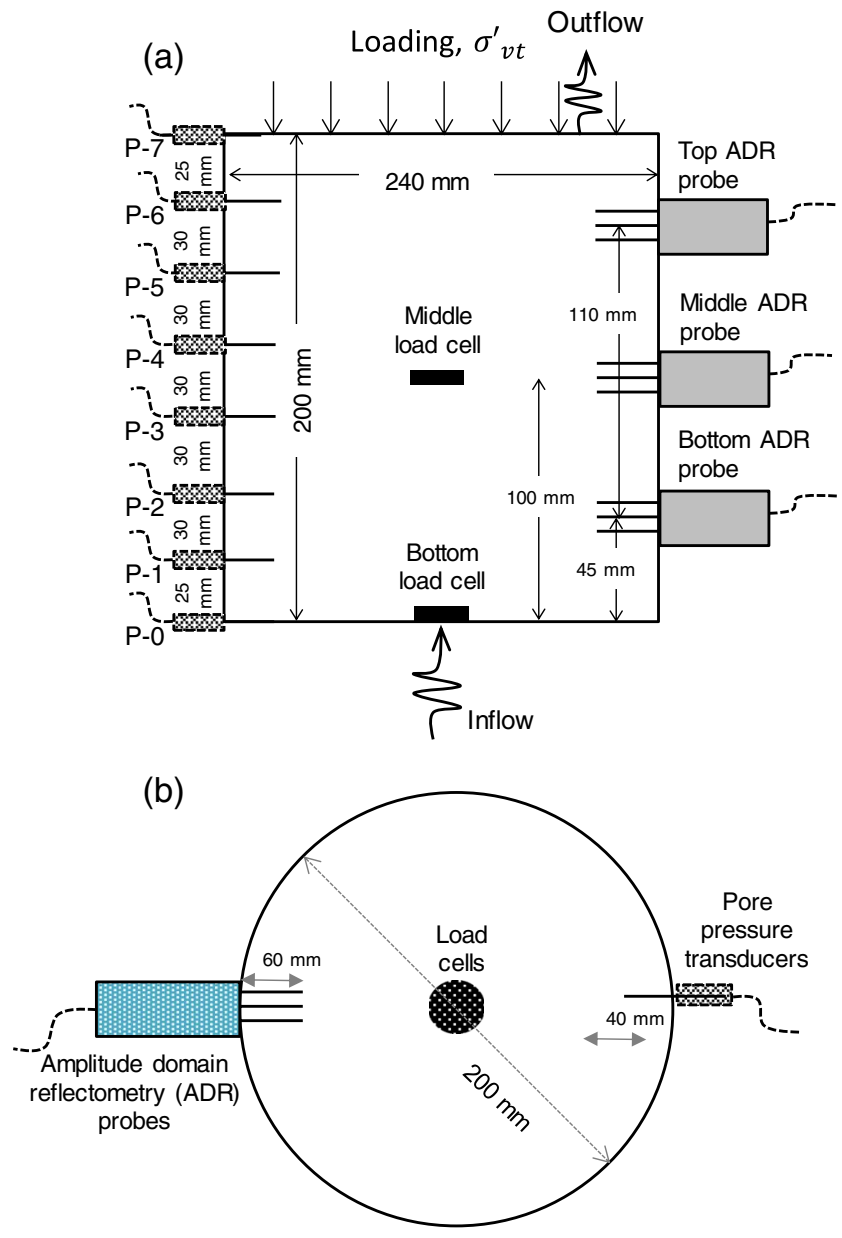

(c)

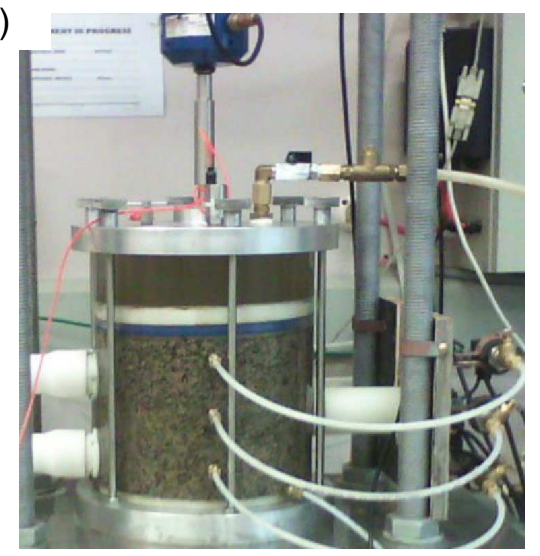

controlling the dry soil mass and using the predetermined limiting void ratios $e_{\min }$ and $e_{\max }$ (ASTM D4253, Standard Test Methods for Maximum Index Density and Unit Weight of Soils Using a Vibratory Table, and ASTM D4254, Standard Test Methods for Minimum Index Density and Unit Weight of Soils and Calculation of Relative Density). The specimen uniformity 
with respect to compaction as well as PSD was ensured through preliminary trials, following the procedures of Indraratna, Israr, and Rujikiatkamjorn (2015). For brevity, several trial specimens were prepared through hand compaction and standard compaction procedures to achieve the target relative densities between 0 and $100 \%$, respectively. Samples at intermediate $R_{d} \approx 30,50,60$, and $70 \%$ were compacted by a $0.75-\mathrm{kg}$ steel rod $(300 \mathrm{~mm}$ long and $20 \mathrm{~mm}$ in diameter). Following the procedure of Das (2008), the imparted compaction energies were estimated to be 26,157 , $263,313,364$, and $564 \mathrm{~kJ} / \mathrm{m}^{3}$ for $R_{d} \approx 5,30,50,60,70$, and $95 \%$, respectively.

The specimen uniformity with respect to compaction was examined by determining the overall density as well as the densities of the small specimens cored within the trial samples. The specimen uniformity with regards to the PSD was assessed through pre- and post-test sieve analyses. The internal erosion is partially represented by the loss of finer fraction that would alter the posttest $C_{u}\left(=d_{60} / d_{10}\right)$ compared to that of the original PSD of tested soil. The specimens were then carefully saturated for 24 to 48 hours after de-airing them using the back pressures of up to $120 \mathrm{kPa}$. The $R_{d}$ was kept $\geq 95 \%$ during phases 2 and 3 , in which the samples were consolidated under the target initial effective stresses before the hydraulic testing.

The upward flow was applied from the bottom at controlled hydraulic pressure and then increased in small steps. The increments in hydraulic pressure and, hence, the hydraulic gradient, $i$, were kept small enough such that the accurate value of the observed critical hydraulic gradient, $i_{c r}$, could be determined at the onset of sample instability. For instance, for narrow gradations $U$ (Uniform) and W (Well-graded), the increments of were kept between 0.04 and 0.05 , whereas, for broad gradations B (Broadlygraded) and $\mathrm{G}$ (Gap-graded), these increments were between 0.02 and 0.025 . The test duration at a certain value of $i$ lasted between 25 and $30 \mathrm{~min}$, beyond which steady state flow was observed, and the next increment of $i$ was then applied for the subsequent stage. The wire mesh did not allow any finer fractions to escape while the specimen was being saturated and tested. The critical onset of internal instability or failure was characterized by the following: (i) variations in the slopes of flow curves (effluent flow rate versus hydraulic gradient), (ii) sudden drop in hydraulic gradient magnitude, (iii) visual variations, e.g., piping, heave, or effluent turbidity $>60$ NTU (Nephelometric Turbidity Unit) for an extended period of time ( $>30 \mathrm{~min}$ ). Further increase in hydraulic pressure beyond the critical onset escalated the erosion, whereas the hydraulic gradient dropped significantly. At such critical onsets, the average and local hydraulic gradients were assumed as the critical hydraulic gradients given by $i_{c r, a}$ and $i_{c r, i j}$, respectively. As shown in Fig. 2, the $i_{c r, a}$ was deduced from the hydraulic head difference between the inflow transducer P-0 and the outflow transducer P-7, whereas the $i_{c r, i j}$ was obtained from the differential head between the two adjacent transducers, e.g., P-0 and P-1,
P-1 and P-2, etc. The tested specimens were then retrieved in five distinct soil layers for post-test forensic analysis to determine any changes in their PSD curves because of erosion.

\section{Test Results and Discussion}

In this study, the following test symbols are used that present information such as the soil type and test condition with the corresponding relative density, effective stress magnitudes, or cyclic frequency values, for example:

- $\mathrm{B} 2-\mathrm{R} 50$ represents sample $\mathrm{B} 2$ compacted at $R_{d} \approx 50 \%$;

- B2-S50 represents sample B2 in a static test under applied stress of $50 \mathrm{kPa}$; and

- B2-C10 represents sample B2 in a cyclic test at $10 \mathrm{~Hz}$ frequency.

\section{PHASE 1: EFFECT OF RELATIVE DENSITY OF SOIL}

This phase was designed with a two-fold objective: namely, (i) to study the effects of compaction on internal stability and (ii) to select a suitable value of $R_{d}$ for sampling in later phases 2 and 3 to make valid comparisons between static and cyclic test results. Fig. 3 shows the variations of effluent flow rate and turbidity with

FIG. 3 Hydraulic test results of effluent flow and turbidity variations with applied hydraulic gradient for selected tests; (a) soil U2 and (b) soil B3.
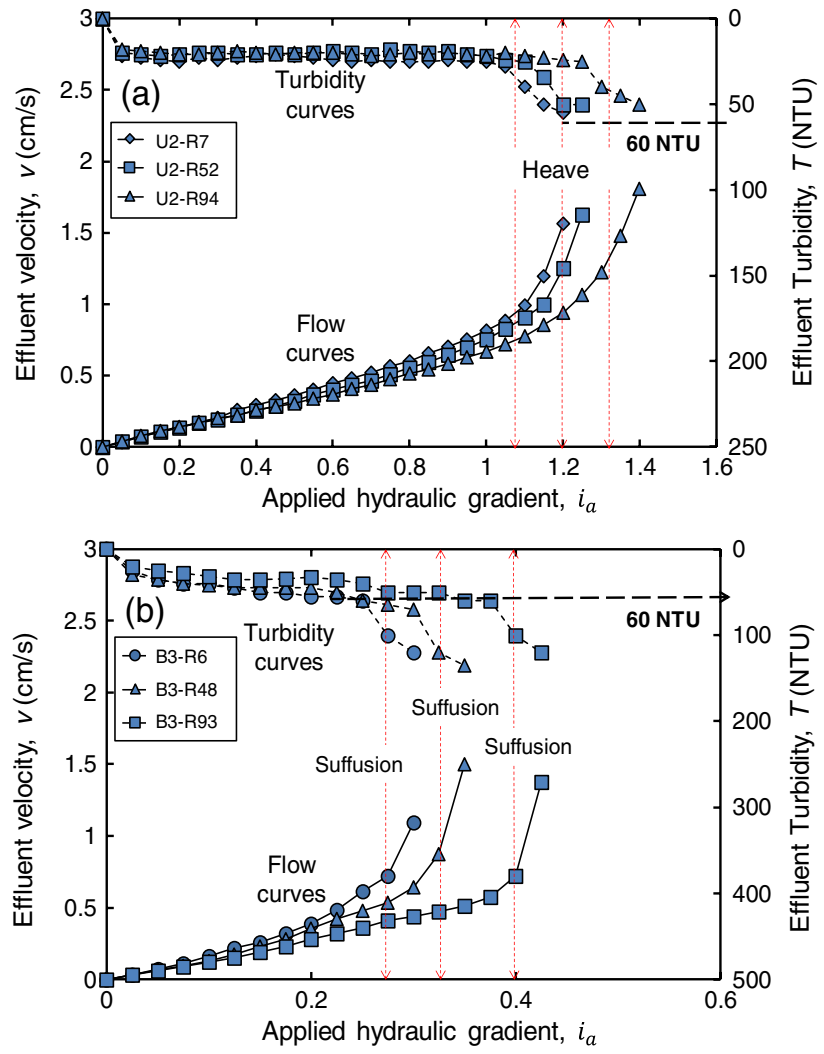
the average hydraulic gradient $\left(i_{a}\right)$, whereby the critical onsets could be identified through variations in the slopes of the flow and turbidity curves. Due to the increase in $R_{d}$ of soil U2 from $7 \%$ to $94 \%$, the slope of the effluent flow rate decreased from $0.78 \mathrm{~cm} / \mathrm{s}$ to $0.62 \mathrm{~cm} / \mathrm{s}$, and the magnitude of $i_{c r, a}$ increased from 1.06 to 1.31 while the effluent turbidity remained well below 60 NTU before the inception of the critical onset of heave. Similarly, the slopes of flow and turbidity curves markedly decreased with the increase in $R_{d}$ of soil B3 (Fig. 3b). Increasing the $R_{d}$ of test samples could significantly increase the magnitudes of $i_{c r, a}$ and reduce the internal erosion, especially in the borderline broadly graded samples B1, B2, and B3 (Fig. 4). For instance, with the increase in $R_{d}$ of broadly graded soil $\mathrm{B} 3$ from $6 \%$ to $93 \%$, the slope of the effluent flow rate decreased from $1.12 \mathrm{~cm} / \mathrm{s}$ to $0.88 \mathrm{~cm} / \mathrm{s}$, and the magnitude of $i_{c r, a}$ increased from 0.28 to 0.40 , while the effluent turbidity remained well below $60 \mathrm{NTU}$ before the inception of suffusion. This stabilizing effect of $R_{d}$ could be attributed to the increased particle packing, i.e., greater number of contacts per particle at higher compaction levels that sufficiently reduced the constriction sizes of stable primary fabric, thereby controlling the erosion of finer fraction (Israr and Indraratna 2017). Nevertheless, the results of the present study clearly demonstrated that soils possess maximum internal stability at higher compaction levels (i.e., $R_{d}$ approaching $100 \%$ ).

FIG. 4 Effect of relative density on (a) critical hydraulic gradient and (b) erosion of finer fraction (Note: solid and hollow symbols represent internally stable and unstable samples, respectively).
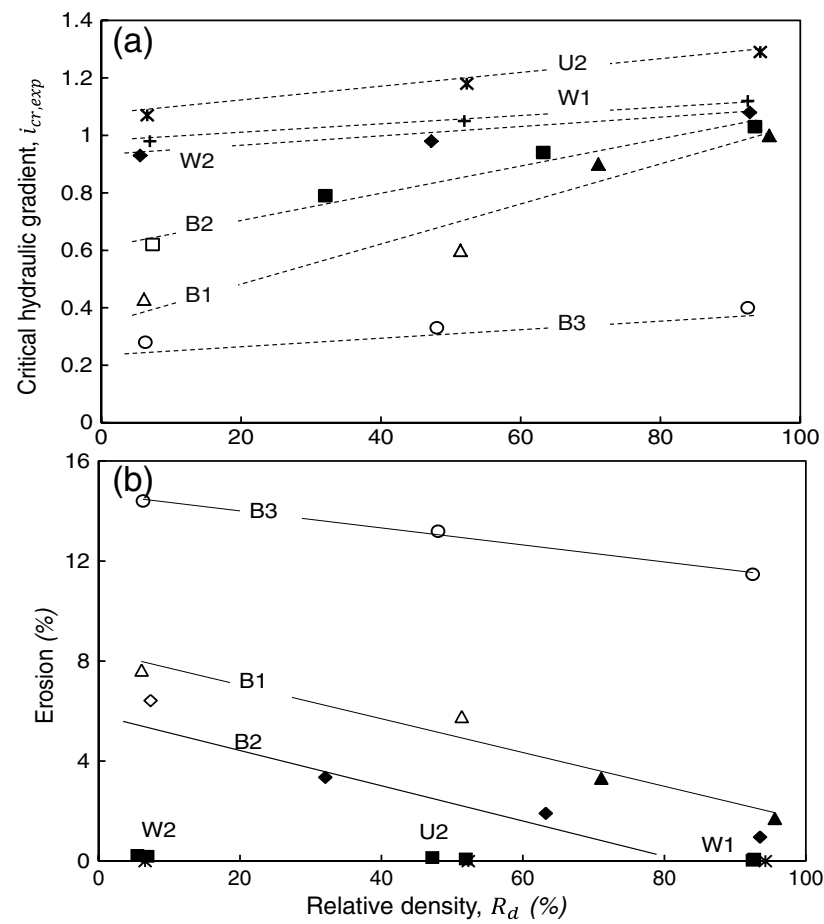

Therefore, the samples for later phases 2 and 3 were prepared at $R_{d} \geq 95 \%$ to ensure uniformity for valid comparisons between static and cyclic responses of test samples.

\section{PHASE 2: EFFECT OF STATIC LOADING MAGNITUDE}

As shown in Fig. 5a, increase in the static loading magnitude proportionally increased the $i_{c r, a}$ and decreased the associated effluent turbidity until reaching the critical onsets, identified by sudden increase in the slopes of flow and turbidity curves. Increase in the magnitude of $i_{c r, a}$ may be attributed to the increased interparticle contact stresses and friction at higher magnitudes of static loading. This also resulted in reduced turbidity of outflow and, hence, the internal erosion. Several past studies reported similar observations, such as Israr, Indraratna, and Rujikiatkamjorn (2016), Zou et al. (2013), Moffat and Fannin (2006), etc. Notably, before the occurrence of suffusion in G2 under static loading, the shapes of flow curves remained identical and the associated effluent turbidities well below 60 NTU. This identical behavior clearly indicated the specimen uniformity and the excellent repeatability of current tests. Nevertheless, the stabilizing effects of static loading in the

FIG. 5 Hydraulic test results for compacted sample G2 under (a) static loading and (b) cyclic loading conditions.
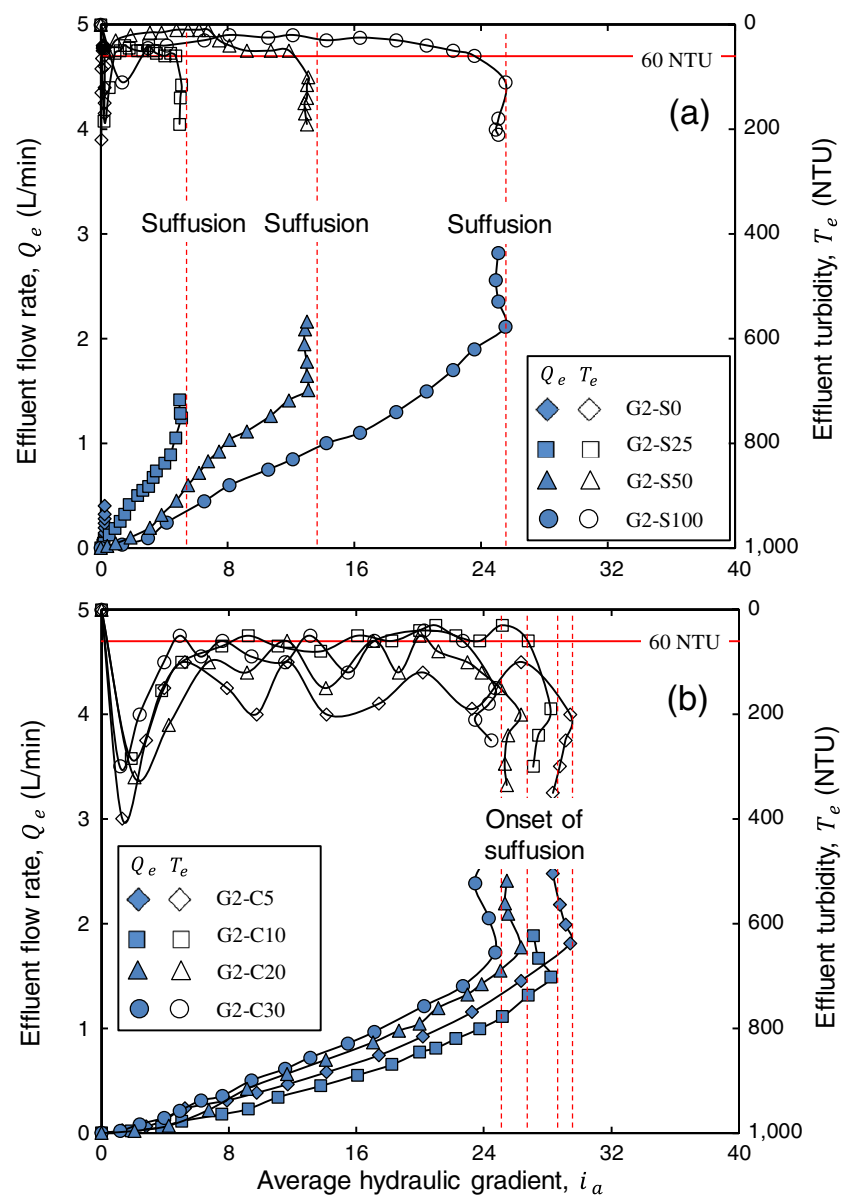
form of an increased critical hydraulic gradient endorses the recommendations of Terzaghi (1939) and Skempton and Brogan (1994) about the use of loaded inverted filters downstream of embankment dams for enhanced stability.

\section{PHASE 3: EFFECT OF CYCLIC LOADING FREQUENCY}

Fig. 5b shows that the flow curves for sample G2 subjected to cyclic loading were less steep than those obtained during static tests (Fig. 5a) in the precritical regime $\left(i_{a}<i_{c r, a}\right)$, which may be due to the densification caused by the cyclic loading. The effluent turbidity curves for soil G2 remained identical in shape until the inception of instability, as shown in Fig. 5b. For instance, the turbidity peaks barely exceeded 200 NTU before the instability commenced and reached up to $380,350,370$, and $300 \mathrm{NTU}$ for tests at 5,10,20, and $30 \mathrm{~Hz}$, respectively. Notably, the $R_{d}$ values of samples were observed to be nearly $100 \%$ after testing under cyclic loading. This could be attributed to the densification effects of cyclic loading in a rigid-wall hydraulic cell that may not be considered significant because it is somehow similar to the standard procedures for compaction involving mechanical efforts and vibration (e.g., ASTM D698, Standard Test Methods for Laboratory Compaction Characteristics of Soil Using Standard Effort $\left(12400 \mathrm{ft}\right.$-lbf/ft $\left.{ }^{3}\left(600 \mathrm{kN}-\mathrm{m} / \mathrm{m}^{3}\right)\right)$ and ASTM D1557, Standard Test Methods for Laboratory Compaction Characteristics of Soil Using Modified Effort (56,000 ft-lbf/ft ${ }^{3}$ $\left.\left.\left(2,700 \mathrm{kN}-\mathrm{m} / \mathrm{m}^{3}\right)\right)\right)$. The number of loading cycles varied with the loading frequency; e.g., up to 0.25 and 1.5 million cycles were applied in tests at 5 and $30 \mathrm{~Hz}$, respectively. The densification due to cyclic load during the initial 25,000 to 40,000 cycles reduced the permeability of test samples. Nevertheless, the blatant agitation due to dynamic loading did not allow the stable constriction network to retain the finer particles (e.g., Xiao, Reddi, and Steinberg 2006), and they continued to erode even at very small $i_{a}$ values, as indicated by the turbidity curves (turbidity $>60$ NTU) in Fig. 5b.

Fig. 6 shows time histories of local hydraulic gradients for sample G2 under static loading $\left(\sigma_{v t}^{\prime}=50 \mathrm{KPa}\right)$ and cyclic loading $\left(\sigma_{v, \text { mean }}^{\prime}=50 \mathrm{KPa}\right)$. As Fig. 6 a shows, the inception of internal instability or the critical onset during static tests could be identified by a sudden drop in the magnitude of hydraulic gradient $i_{i j}$, which was characterized as the local critical hydraulic gradient $\left(i_{c r, i j}\right)$. This critical onset is indicated by the corresponding $i_{c r, i j}$ value on the solid curve, which represents the critical soil layer 45 , where instability commenced and visual signs of excessive erosion were also recorded (i.e., suffusion). As previously shown in Fig. 5, this critical onset was temporally consistent with the one identified from the variations of flow and turbidity curves. Fig. $6 \mathbf{b}$ shows the time histories of $i_{c r, i j}$ for sample G2 subjected to cyclic loading at $20 \mathrm{~Hz}$ (i.e., G2-C20). The instability commenced in the same soil layer, 45 ; however, at $i_{c r, i j}=43.3$, nearly twice as much was observed during the static test $\left(i_{c r, i j}=21.9\right)$. Notably, the $i_{c r, a}$ values remained generally smaller and consistent irrespective of the
FIG. 6 Time histories of local hydraulic gradients for sample G2: (a) static tests and (b) cyclic tests.
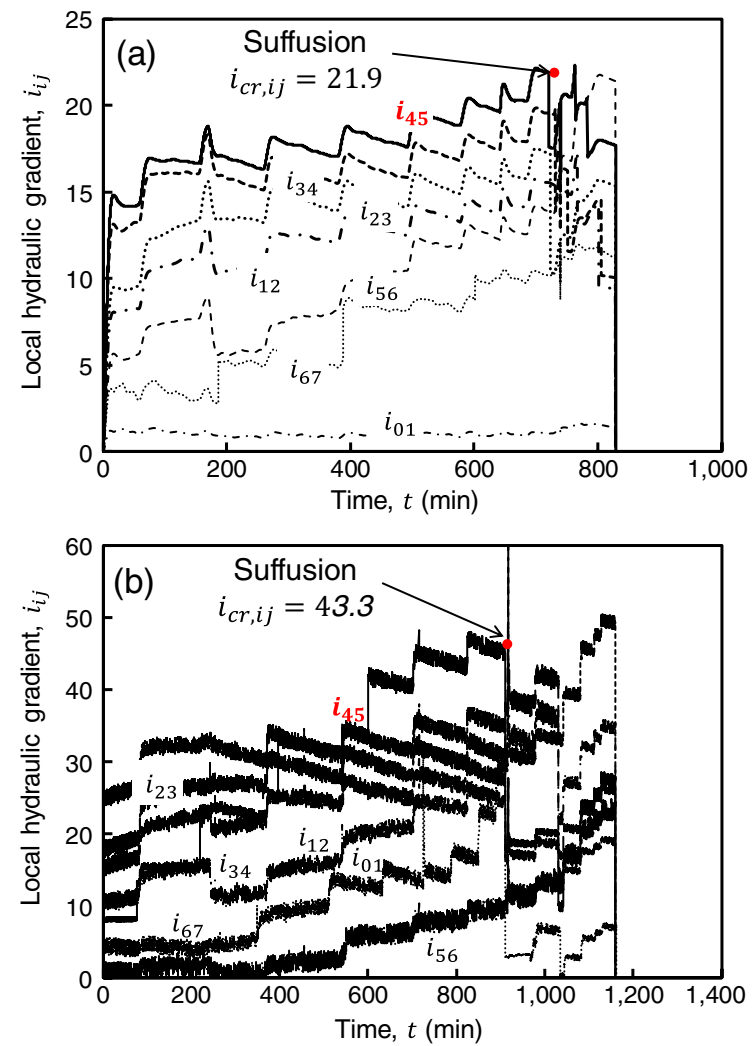

loading condition, unlike the values of $i_{c r, i j}$, which tended to be up to two times greater under cyclic loading. A probable explanation for this discrepancy would be the development of excess pore water pressures due to a large reduction in the permeability of the test sample under cyclic loading. This is also consistent with reductions in the slope of flow curves, as previously discussed in Fig. 5b.

Figs. 7 and 8 show the comparisons between the effects of static loading and cyclic frequency on seepage-induced responses of selected samples. As a result of increase in static loading magnitude from 0 to $100 \mathrm{kPa}$, the magnitudes of $i_{c r, a}$ and $i_{c r, i j}$ increased, whereas that of erosion decreased, thereby increasing the internal stability of the soils. The increased effective stress on erodible fines required larger hydraulic gradients to dislodge them from pore spaces of the stable fabric. However, under cyclic loading, the magnitudes of $i_{c r, a}$ decreased, whereas those of $i_{c r, i j}$ and internal erosion increased with the increase in cyclic loading frequency. Here, the agitation due to cyclic loading did not allow the stable constrictions to develop, whereas the associated pore water pressure induced a larger $i_{c r, i j}$ to trigger the erosion of fines from the pore spaces (Fig. 7b). As Fig. 7b shows, the overall erosion of fines remained insensitive to the cyclic loading frequency 
FIG. 7 Variations of critical hydraulic gradient for selected samples W2 and G2 against (a) magnitude of applied static normal stress and (b) frequency of cyclic loading.
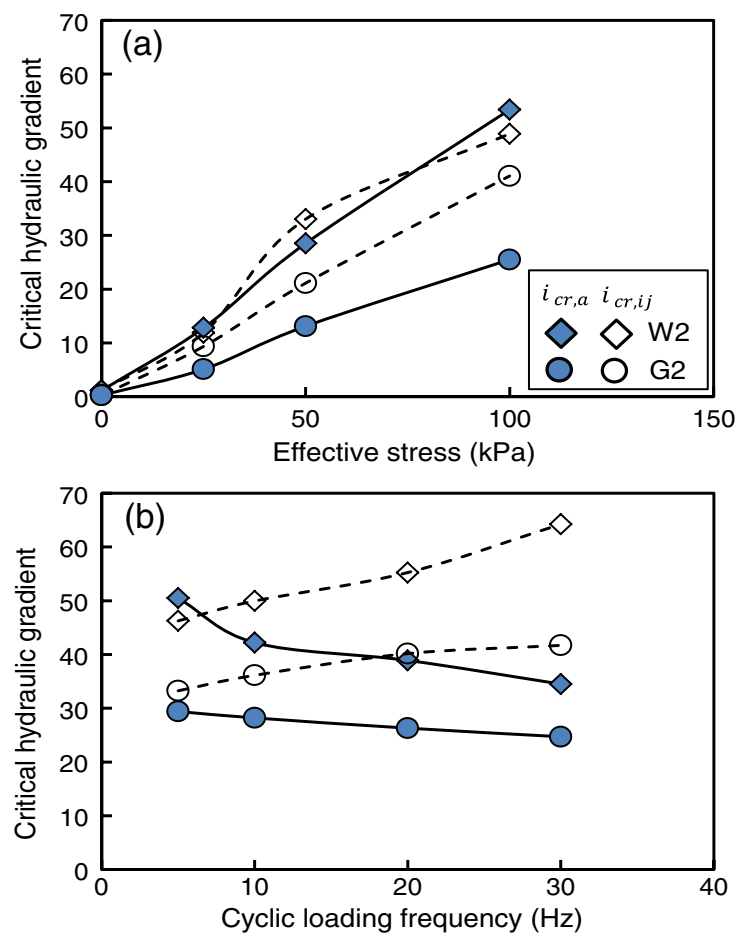

for soils W2, B1, and B2, whereas that for soil G2 increased from $12.2 \%$ at $5 \mathrm{~Hz}$ to $13.8 \%$ at $30 \mathrm{~Hz}$. This $1.6 \%$ increase in internal erosion seems inconsistent with the results of decreasing turbidity peaks for soil G2 at higher frequencies, as previously shown in Fig. 5b. A probable explanation would be that the reductions in turbidity peaks at higher frequencies are the effects of compaction due to cyclic loading, whereby a sample at $30 \mathrm{~Hz}$ would densify to $R_{d} \approx 100 \%$ three times quicker than the same at $10 \mathrm{~Hz}$. Whereas the increased erosion may be attributed to severity of test conditions such as excessive vibrations and transient pore water pressures at higher frequencies (Israr 2016). This is also consistent with the results of local hydraulic gradient $\left(i_{c r, i j}\right)$ histories reported in Fig. 6, where comparatively higher $i_{c r, i j}$ were recorded during cyclic tests compared to those from static tests. The increasing trends of $i_{c r, i j}$ and decreasing trends of $i_{c r, a}$ from 5 to $30 \mathrm{~Hz}$ illustrate that the instability was progressively higher and quicker under cyclic loading than static loading. Nevertheless, an increasing magnitude of static loading possesses stabilizing effects, thereby reducing the percentage of internal erosion while requiring larger magnitudes of $i_{c r, i j}$ and $i_{c r, a}$ to trigger internal instability. In contrast, the strong seepage forces combined with perturbation and excess pore water pressure due to cyclic loading could trigger excessive and premature internal erosion in soils.
FIG. 8 Variations of percentage erosion of finer fraction for samples W2, B1, B2, and G2 against (a) magnitude of applied static normal stress and (b) frequency of cyclic loading
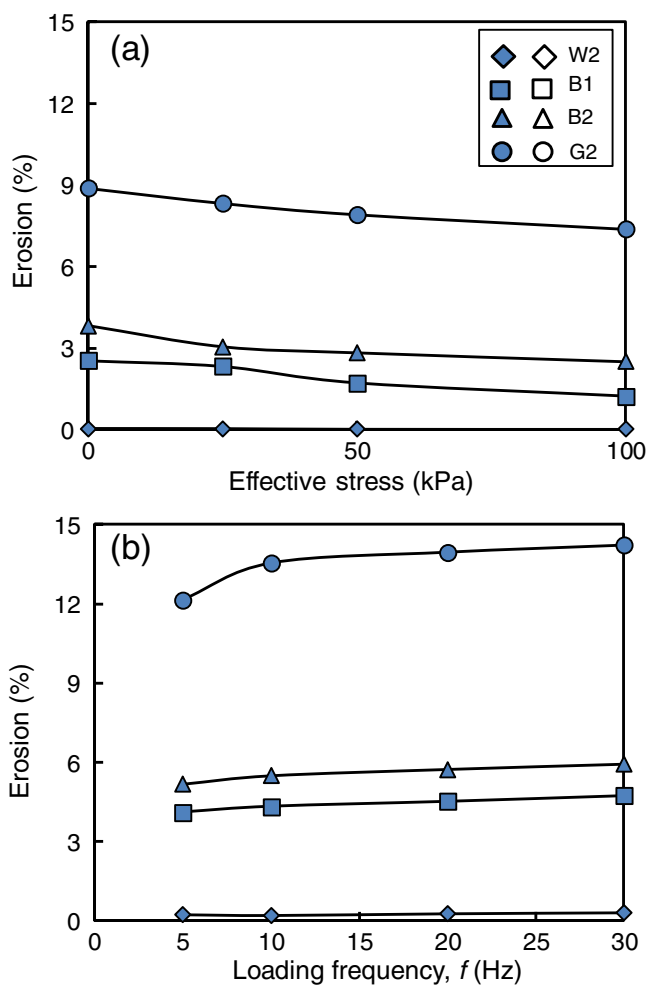

\section{Internal Instability Potential}

\section{EXPERIMENTAL OBSERVATION}

The current rationale to characterize an internally stable specimen included: (i) unaltered shape and $C_{u}$ value of PSD curve for a specimen, (ii) less than $4 \%$ internal erosion of fines, and (iii) development of heave at $i_{c r} \geq i_{c t}$ from classical piping theory of Terzaghi (Indraratna, Israr, and Rujikiatkamjorn 2015; Skempton and Brogan 1994; Kenney and Lau 1985). The analysis of static tests revealed that soils B1 and B2 showed internal instability at $R_{d} \leq 51 \%$ and $R_{d} \leq 7 \%$, respectively, whereas soils G1 and G2 proved to be internally unstable at all compaction levels. The rest of the soils could be characterized as internally stable at all relative densities. This is because the constrictions formed by the nonerodible coarse particles of loosely compacted B1 and B2 and gap-graded soils G1 and G2 could not retain their erodible fines, allowing well over $4 \%$ internal erosion and resulting in permanent changes to their original PSD curves. In contrast, the constriction network of the rest of the internally stable soils was sufficiently fine to retain their erodible finer fractions. For instance, particle and constriction size distributions for soil B1 at all relative densities are plotted in Fig. $\mathbf{8}$, where $d_{c 35}^{c}$ corresponding to $R_{d} \leq 51 \%$ is larger than $d_{85, S A}^{f}$. This clearly indicates that all 
particle sizes up to $d_{85, S A}^{f}$ can erode through the controlling constriction size $d_{c 35}^{c}$, thereby geometrically proving soil B1 as internally unstable at $R_{d} \leq 51 \%$, which is fully consistent with the above test results. However, under cyclic loading, soils B1, B2, B3, G1, and G2 showed internal instability even when they were compacted at $R_{d} \geq 95 \%$ (Tables 2-4). A similar analysis of particle and constriction size distributions revealed that these soils were geometrically unstable because their $d_{c 35}^{c}$ was larger than $d_{85, S A}^{f}$, except in soils B1 and B2. A probable explanation for B1 and B2 still exhibiting internal instability would be the disturbance of the constriction network due to the agitation induced by the cyclic loading (e.g., Xiao, Reddi, and Steinberg 2006; Israr and Indraratna 2017). Given that constriction sizes can vary between the densest and the loosest limits (Locke, Indraratna, and Adikari 2001), the finer fraction would escape when the geometrical requirement is met (i.e., $d_{c 35}^{c}>d_{85, S A}^{f}$ ), as illustrated in Fig. 9. For a given soil, an increased internal erosion indicated by larger turbidity peaks during cyclic tests compared to those during static tests also lends support to the above explanation, as previously shown in Fig. 5.

TABLE 2 Summary of test results from phase $1(\sqrt{ }=$ Stable, $X=$ Unstable).

\begin{tabular}{|c|c|c|c|c|c|c|}
\hline \multirow[b]{2}{*}{ Test No. } & \multirow[b]{2}{*}{ Sample ID } & \multirow[b]{2}{*}{$R_{d}(\%)$} & \multicolumn{4}{|c|}{ Internal Stability Assessment } \\
\hline & & & EXP & $\mathrm{KL}$ & $\mathrm{KZ}$ & IE \\
\hline 1 & U1 & 96 & $\sqrt{ }$ & $\sqrt{ }$ & $\sqrt{ }$ & $\sqrt{ }$ \\
\hline 2 & $\mathrm{U} 2$ & 7 & $\sqrt{ }$ & $\sqrt{ }$ & $\sqrt{ }$ & $\sqrt{ }$ \\
\hline 3 & $\mathrm{U} 2$ & 52 & $\sqrt{ }$ & $\sqrt{ }$ & $\sqrt{ }$ & $\sqrt{ }$ \\
\hline 4 & $\mathrm{U} 2$ & 94 & $\sqrt{ }$ & $\sqrt{ }$ & $\sqrt{ }$ & $\sqrt{ }$ \\
\hline 5 & U3 & 95 & $\sqrt{ }$ & $\sqrt{ }$ & $\sqrt{ }$ & $\sqrt{ }$ \\
\hline 6 & W1 & 7 & $\sqrt{ }$ & $\sqrt{ }$ & $\sqrt{ }$ & $\sqrt{ }$ \\
\hline 7 & W1 & 52 & $\sqrt{ }$ & $\sqrt{ }$ & $\sqrt{ }$ & $\sqrt{ }$ \\
\hline 8 & W1 & 93 & $\sqrt{ }$ & $\sqrt{ }$ & $\sqrt{ }$ & $\sqrt{ }$ \\
\hline 9 & W2 & 6 & $\sqrt{ }$ & $\sqrt{ }$ & $\sqrt{ }$ & $\sqrt{ }$ \\
\hline 10 & W2 & 47 & $\sqrt{ }$ & $\sqrt{ }$ & $\sqrt{ }$ & $\sqrt{ }$ \\
\hline 11 & W2 & 93 & $\sqrt{ }$ & $\sqrt{ }$ & $\sqrt{ }$ & $\sqrt{ }$ \\
\hline 12 & B1 & 6 & $\mathrm{X}$ & $\sqrt{ }$ & $\sqrt{ }$ & $\mathrm{X}$ \\
\hline 13 & B1 & 51 & $\mathrm{X}$ & $\sqrt{ }$ & $\sqrt{ }$ & $\mathrm{X}$ \\
\hline 14 & B1 & 71 & $\sqrt{ }$ & $\sqrt{ }$ & $\sqrt{ }$ & $\sqrt{ }$ \\
\hline 15 & B1 & 96 & $\sqrt{ }$ & $\sqrt{ }$ & $\sqrt{ }$ & $\sqrt{ }$ \\
\hline 16 & B2 & 7 & $\mathrm{X}$ & $\sqrt{ }$ & $\mathrm{X}$ & $\mathrm{X}$ \\
\hline 17 & B2 & 32 & $\sqrt{ }$ & $\sqrt{ }$ & $\mathrm{X}$ & $\sqrt{ }$ \\
\hline 18 & B2 & 63 & $\sqrt{ }$ & $\sqrt{ }$ & $\mathrm{X}$ & $\sqrt{ }$ \\
\hline 19 & B2 & 94 & $\sqrt{ }$ & $\sqrt{ }$ & $\mathrm{X}$ & $\sqrt{ }$ \\
\hline 20 & B3 & 6 & $\mathrm{X}$ & $\mathrm{X}$ & $\mathrm{X}$ & $\mathrm{X}$ \\
\hline 21 & B3 & 48 & $X$ & $\mathrm{X}$ & $\mathrm{X}$ & $\mathrm{X}$ \\
\hline 22 & B3 & 93 & $X$ & $\mathrm{X}$ & $\mathrm{X}$ & $X$ \\
\hline 23 & G1 & 95 & $\mathrm{X}$ & $\mathrm{X}$ & $\mathrm{X}$ & $\mathrm{X}$ \\
\hline 24 & G2 & 96 & $\mathrm{X}$ & $\mathrm{X}$ & $X$ & $X$ \\
\hline
\end{tabular}

Notes: EXP = experimental, KL = Kenney and Lau (1985), KZ = Kézdi (1979), and IE $=$ Indraratna, Israr, and Rujikiatkamjorn (2015)
TABLE 3 Summary of test results from phase $2(\sqrt{ }=$ Stable, $X=$ Unstable)

Internal Stability Assessment

\begin{tabular}{|c|c|c|c|c|c|c|}
\hline \multirow[b]{2}{*}{ Test No. } & \multirow[b]{2}{*}{ Sample ID } & \multirow[b]{2}{*}{$f^{*} \mathrm{~Hz}$} & \multicolumn{4}{|c|}{ Internal Stability Assessment } \\
\hline & & & EXP & $\mathrm{KL}$ & $\mathrm{KZ}$ & IE \\
\hline 25 & $\mathrm{U} 1$ & 50 & $\sqrt{ }$ & $\sqrt{ }$ & $\sqrt{ }$ & $\sqrt{ }$ \\
\hline 26 & $\mathrm{U} 3$ & 50 & $\sqrt{ }$ & $\sqrt{ }$ & $\sqrt{ }$ & $\sqrt{ }$ \\
\hline 27 & W2 & 25 & $\sqrt{ }$ & $\sqrt{ }$ & $\sqrt{ }$ & $\sqrt{ }$ \\
\hline 28 & W2 & 50 & $\sqrt{ }$ & $\sqrt{ }$ & $\sqrt{ }$ & $\sqrt{ }$ \\
\hline 29 & W2 & 100 & $\sqrt{ }$ & $\sqrt{ }$ & $\sqrt{ }$ & $\sqrt{ }$ \\
\hline 30 & B1 & 25 & $\mathrm{X}$ & $\sqrt{ }$ & $\sqrt{ }$ & $\mathrm{X}$ \\
\hline 31 & B1 & 50 & $\sqrt{ }$ & $\sqrt{ }$ & $\sqrt{ }$ & $\sqrt{ }$ \\
\hline 32 & B1 & 100 & $\sqrt{ }$ & $\sqrt{ }$ & $\sqrt{ }$ & $\sqrt{ }$ \\
\hline 33 & B2 & 25 & $\mathrm{X}$ & $\sqrt{ }$ & $\mathrm{X}$ & $\mathrm{X}$ \\
\hline 34 & B2 & 50 & $\sqrt{ }$ & $\sqrt{ }$ & $\mathrm{X}$ & $\sqrt{ }$ \\
\hline 35 & B2 & 100 & $\sqrt{ }$ & $\sqrt{ }$ & $\mathrm{X}$ & $\sqrt{ }$ \\
\hline 36 & G1 & 50 & $\mathrm{X}$ & $\mathrm{X}$ & $\mathrm{X}$ & $\mathrm{X}$ \\
\hline 37 & G2 & 25 & $X$ & $\mathrm{X}$ & $\mathrm{X}$ & $\mathrm{X}$ \\
\hline 38 & G2 & 50 & $X$ & $\mathrm{X}$ & $\mathrm{X}$ & $\mathrm{X}$ \\
\hline 39 & G2 & 100 & $X$ & $\mathrm{X}$ & $\mathrm{X}$ & $\mathrm{X}$ \\
\hline
\end{tabular}

${ }^{*} \sigma_{v t}^{\prime}=$ vertical effective stress.

TABLE 4 Summary of test results from phase $3(\sqrt{ }=$ Stable, $X=$ Unstable).

\begin{tabular}{|c|c|c|c|c|c|c|}
\hline \multirow[b]{2}{*}{ Test No. } & \multirow[b]{2}{*}{ Sample ID } & \multirow[b]{2}{*}{$f^{\star} \mathrm{Hz}$} & \multicolumn{4}{|c|}{ Internal Stability Assessment } \\
\hline & & & EXP & KL & $\mathrm{KZ}$ & MIE \\
\hline 40 & U1 & 5 & $\sqrt{ }$ & $\sqrt{ }$ & $\sqrt{ }$ & $\sqrt{ }$ \\
\hline 41 & U3 & 5 & $\sqrt{ }$ & $\sqrt{ }$ & $\sqrt{ }$ & $\sqrt{ }$ \\
\hline 42 & W2 & 5 & $\sqrt{ }$ & $\sqrt{ }$ & $\sqrt{ }$ & $\sqrt{ }$ \\
\hline 43 & W2 & 10 & $\sqrt{ }$ & $\sqrt{ }$ & $\sqrt{ }$ & $\sqrt{ }$ \\
\hline 44 & W2 & 20 & $\sqrt{ }$ & $\sqrt{ }$ & $\sqrt{ }$ & $\sqrt{ }$ \\
\hline 45 & W2 & 30 & $\sqrt{ }$ & $\sqrt{ }$ & $\sqrt{ }$ & $\sqrt{ }$ \\
\hline 46 & B1 & 5 & $\mathrm{X}$ & $\sqrt{ }$ & $\sqrt{ }$ & $\mathrm{X}$ \\
\hline 47 & B1 & 10 & $\mathrm{X}$ & $\sqrt{ }$ & $\sqrt{ }$ & $\mathrm{X}$ \\
\hline 48 & B1 & 20 & $\mathrm{X}$ & $\sqrt{ }$ & $\sqrt{ }$ & $\mathrm{X}$ \\
\hline 49 & B1 & 30 & $\mathrm{X}$ & $\sqrt{ }$ & $\sqrt{ }$ & $\mathrm{X}$ \\
\hline 50 & B2 & 5 & $\mathrm{X}$ & $\sqrt{ }$ & $\mathrm{X}$ & $\mathrm{X}$ \\
\hline 51 & B2 & 10 & $\mathrm{X}$ & $\sqrt{ }$ & $\mathrm{X}$ & $\mathrm{X}$ \\
\hline 52 & B2 & 20 & $\mathrm{X}$ & $\sqrt{ }$ & $\mathrm{X}$ & $\mathrm{X}$ \\
\hline 53 & B2 & 30 & $\mathrm{X}$ & $\sqrt{ }$ & $\mathrm{X}$ & $\mathrm{X}$ \\
\hline 54 & G1 & 5 & $\mathrm{X}$ & $\mathrm{X}$ & $\mathrm{X}$ & $\mathrm{X}$ \\
\hline 55 & G1 & 10 & $\mathrm{X}$ & $\mathrm{X}$ & $\mathrm{X}$ & $\mathrm{X}$ \\
\hline 56 & G1 & 15 & $\mathrm{X}$ & $\mathrm{X}$ & $\mathrm{X}$ & $\mathrm{X}$ \\
\hline 57 & G1 & 20 & $\mathrm{X}$ & $\mathrm{X}$ & $\mathrm{X}$ & $\mathrm{X}$ \\
\hline 58 & G2 & 5 & $\mathrm{X}$ & $\mathrm{X}$ & $\mathrm{X}$ & $\mathrm{X}$ \\
\hline 59 & G2 & 10 & $\mathrm{X}$ & $\mathrm{X}$ & $\mathrm{X}$ & $\mathrm{X}$ \\
\hline 60 & G2 & 20 & $\mathrm{X}$ & $\mathrm{X}$ & $\mathrm{X}$ & $\mathrm{X}$ \\
\hline 61 & G2 & 30 & $\mathrm{X}$ & $\mathrm{X}$ & $\mathrm{X}$ & $\mathrm{X}$ \\
\hline
\end{tabular}

${ }^{*} f=$ cyclic loading frequency and MIE = modified method of Indraratna, Israr, and Rujikiatkamjorn (2015). 
FIG. 9 Effects of relative density on constriction size distribution of stable coarse fraction and illustration of its capacity to retain the finer fraction for sample B1.

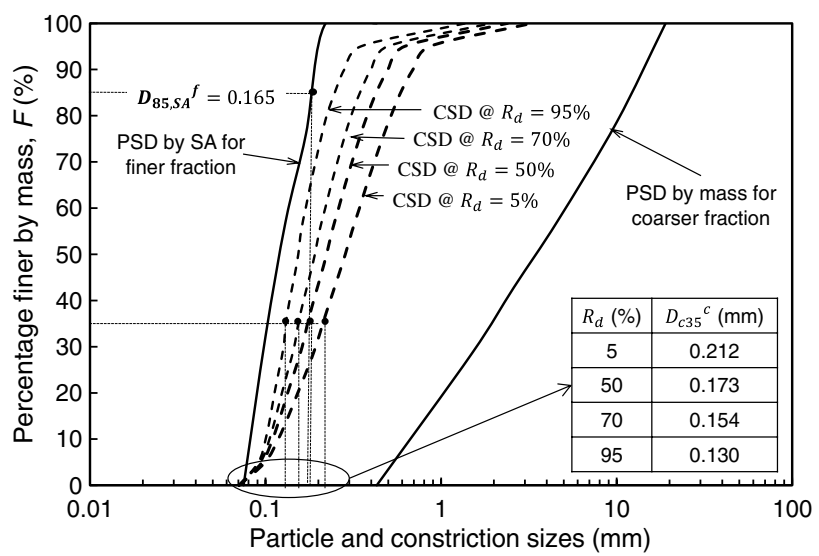

\section{EXISTING CRITERIA FOR INTERNAL INSTABILITY}

All specimens of this study were reexamined using two wellaccepted PSD-based and one CSD-based geometrical criteria, as shown in Tables 2-4. Note that the geometrical approach referred to herein is the one that is based on either particle or constriction sizes to determine the susceptibility of soils to internal instability, e.g., the criteria of Kézdi (1979), Kenney and Lau (1985), and Indraratna, Israr, and Rujikiatkamjorn (2015). The acronyms $\mathrm{KL}, \mathrm{KZ}$, and IE define the criteria from Kenney and Lau (1985), Kézdi (1979), and Indraratna, Israr, and Rujikiatkamjorn (2015), respectively, whereas EXP represents the experimental results of this study.

The analysis of samples from phase 1 revealed that the KL and $\mathrm{KZ}$ criteria yielded three and four inconsistent predictions, respectively. Given that the level of compaction was varied during this phase, the above PSD-based criteria failed to capture its effects in borderline specimens B1 and B2. As a result of increase in $R_{d}$, the constrictions become increasingly finer and consequently retain the characteristic particle size corresponding to 85th percentile finer by the surface area $\left(d_{85, S A}^{f}\right)$ for the finer fraction to initiate the process of local self-filtering (Fig. 10).

Not surprisingly, the IE criterion, which is equally sensitive to the PSD and $R_{d}$ of soils, assessed the current test results with $100 \%$ success. During phase 2, the PSD criteria showed insensitivity to the static loading magnitude, where the $\mathrm{KL}$ and $\mathrm{KZ}$ criteria resulted in two and three inconsistent predictions, respectively. However, the predictions from IE agreed fully with the current EXP results (Table 3). Table 4 presents the results of internal stability assessments for test specimens subjected to cyclic loading. Unlike the predictions for static tests, none of the existing criteria

FIG. 10

Illustrations of seepage induced failures under static loading conditions for selected tests; (a) W2-S50, (b) B1-S50, (c) B2-S50, and (d) G2-S50.
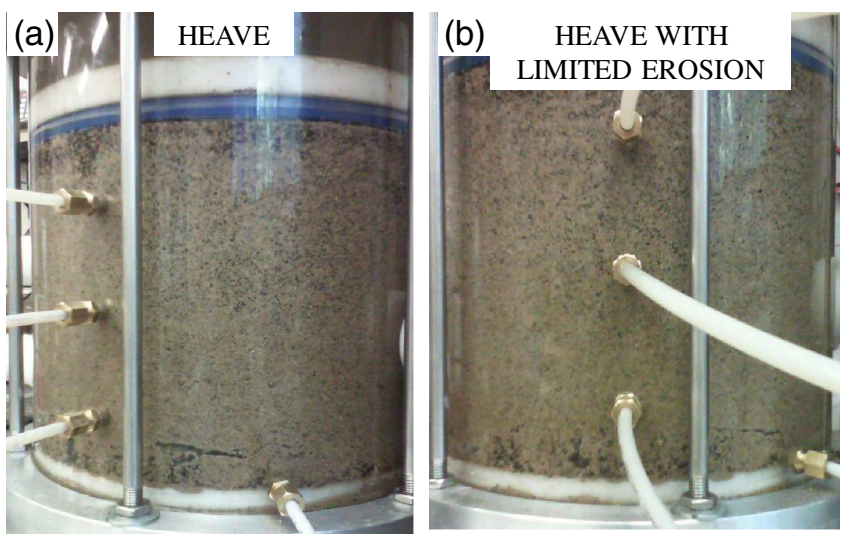

(c) LIMITED EROSION
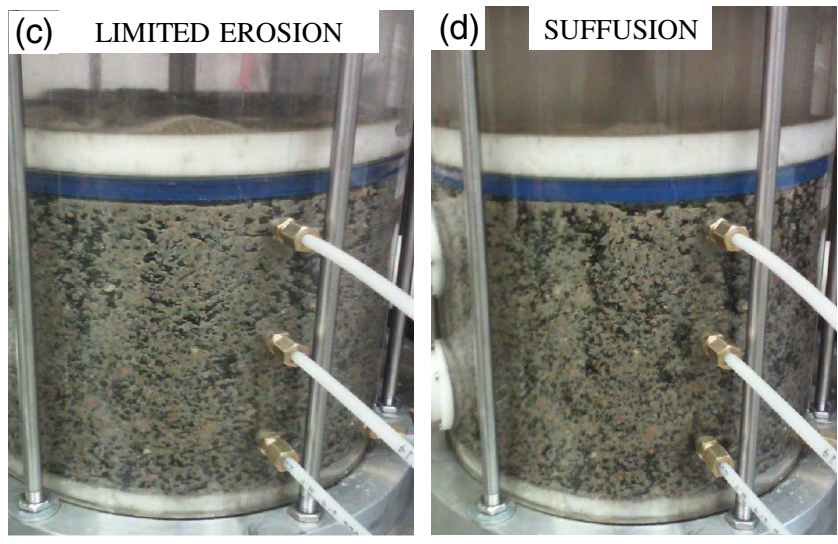
showed $100 \%$ success. For instance, KL, KZ, and IE yielded eight, four, and eight inconsistent predictions, respectively.

The agitation and companion pore water pressure generated through cyclic loading deteriorated the stable constriction network of primary fabric, thereby widening some of the smaller constrictions and vice versa (Trani and Indraratna 2010; Xiao, Reddi, and Steinberg 2006). Consequently, this would allow the already retained fines to escape with the effluent through widened constrictions to trigger suffusion failure. Note that the geometrical approaches described previously do not capture this constriction deterioration mechanism, resulting in inconsistent assessments. In this study, the existing CSD-based approach of Indraratna, Israr, and Rujikiatkamjorn (2015) is modified to capture these effects of cyclic loading, namely, the modified Indraratna, Israr, and Rujikiatkamjorn (2015) criterion, which is abbreviated as MIE in Table 4.

\section{PROPOSED REVISION FOR CYCLIC CONDITIONS AND VALIDATION}

As discussed in a previous section, the criterion of Indraratna, Israr, and Rujikiatkamjorn (2015) is expressed as a ratio of constriction size of stable coarser fraction $D_{c 35}^{c}$ and particle size of finer fraction $d_{85, S A}^{f}(\mathrm{Eq} 1)$. Note that the constriction sizes can only vary between the limiting range of loosest and densest sizes, depending upon the particle packing (i.e., compaction). As shown by phase 1 results, soil possesses the smallest constriction sizes and, hence, greater internal stability at higher compaction levels $\left(R_{d} \approx 100 \%\right)$. In contrast, its internal instability potential would be higher at lower compaction levels due to wider constrictions. Therefore, to assess the potential of granular filters for internal instability under cyclic loading, it would be conservative to use the loosest controlling constriction size $D_{c 35}^{c \text { loosest }}$, corresponding to $R_{d}=0 \%$ in Eq 1 to assess internal stability under cyclic loading:

$$
D_{c 35}^{c \text { loosest }} / d_{85, S A}^{f} \leq 1
$$

where $d_{85, S A}^{f}$ is the particle size at the 85 th percentile finer by surface area for the finer fraction. For soils to suffer from suffusion, the geometrical criterion given by Eq 1 (i.e., eroding particle < constriction size) and the hydromechanical criterion, the critical hydraulic gradient at minimum effective stress in soil should meet simultaneously (Israr 2016; Skempton and Brogan 1994; Moffat and Fannin 2011). Notably, very large hydraulic gradients accompanied by cyclic loading were applied here to simulate the worst possible hydromechanical scenarios, and this resulted in excessive erosion from soils B1, B2, B3, G1, and G2 (i.e., meeting the hydromechanical requirement). To examine whether or not the above geometrical requirement was met when instability occurred, the proposed criterion (Eq 2) was applied to the current results, and the findings are summarized in Table 4. The assessments based on Eq 2 agreed completely with the experimental observations of this study, whereby the predictions are fully consistent with the experimental observations (i.e., $100 \%$ success).

\section{Modes of Seepage Failures}

\section{STATIC LOADING TESTS}

Fig. 10 illustrates the types of seepage-induced failures in selected specimens under static loading. The well-graded specimen (W1) exhibited heave failure with no erosion and therefore remained internally stable at all relative densities. The broadly graded specimens (B1 and B2) showed internal stability only at higher compaction levels, whereas the gap-graded soil G2 suffered from suffusion at all relative density values, although the amount of erosion reduced with the increase in $R_{d}$. Similarly, the magnitudes of $i_{c r}$ increased and the magnitude of erosion decreased with the increase in magnitude of static loading. In summary, all specimens showed enhanced stability at higher $R_{d}$ under static loading except the gap-graded soils, which failed to show internal stability.

\section{CYCLIC LOADING TESTS}

Not surprisingly, abrupt compressions of samples were recorded due to cyclic densification that incurred permeability reductions.

FIG. 11 Illustrations of seepage induced failures under cyclic loading conditions for selected tests; (a) W2-C2O, (b) B1-C2O, (c) B2 C2O, and (d) G2-C2O.
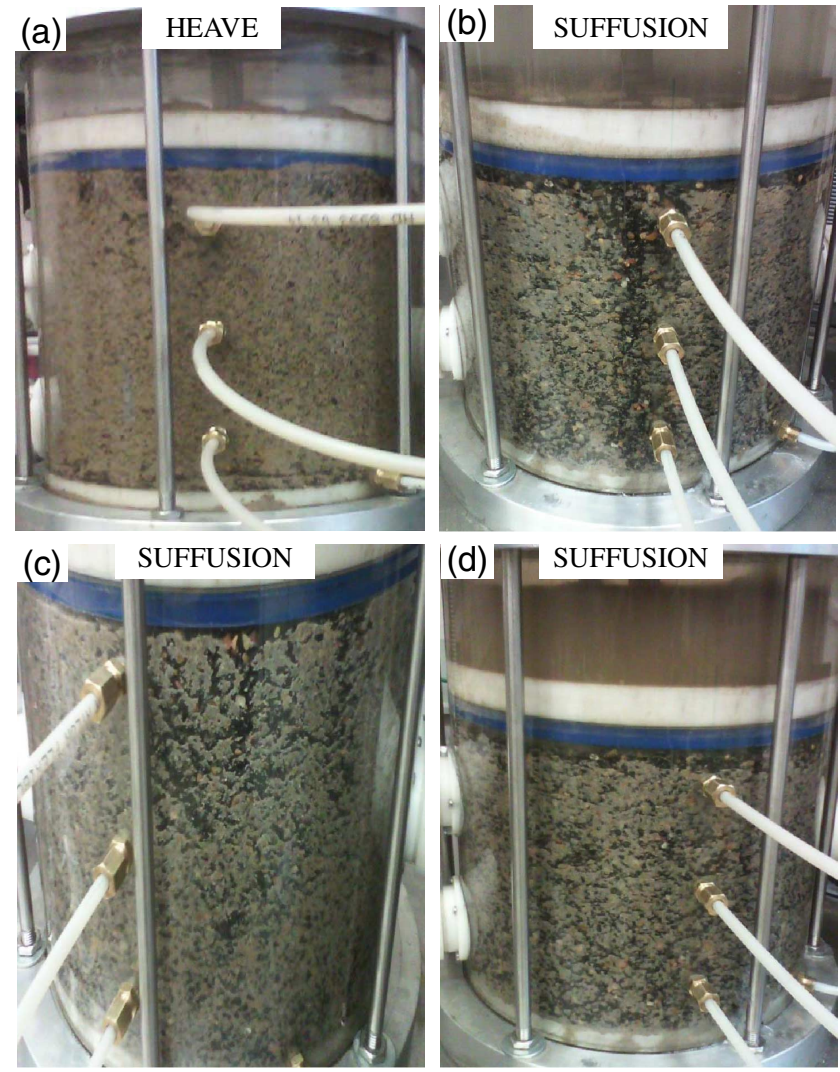
Additionally, the cyclic loads imparted physical disturbance to the specimens in the form of agitation and generated the pore pressure due to low permeability. The constriction network of coarse fraction could not maintain its stability, thereby allowing drag and hydrodynamic forces to trigger erosion of fines from the pore spaces. The internal erosion became excessive at higher frequencies, whereby none of the specimens showed internal stability under cyclic loading except soils $U$ and $W$ (Fig. 11). The analysis also revealed that the response of a compacted $\left(R_{d} \geq 95 \%\right)$ specimen under cyclic loading became almost similar to that of a loose specimen $\left(R_{d}<5 \%\right)$ under static conditions.

\section{FAILURE MECHANISMS AND GOVERNING FACTORS}

Fig. 12 shows the generalized mechanisms for two types of seepage-induced failures in granular soils. As shown in Fig. 12a, an internally unstable soil suffers from suffusion at critical hydraulic gradients smaller than that for quicksand conditions, i.e., $i_{c r, t}=$ $\gamma_{s} / \gamma_{w}=1$, where $\gamma_{s}$ and $\gamma_{w}$ define the unit weights of soil and water, respectively (Terzaghi 1939).

The washout of finer particles incurs changes in the original PSD of soils, thereby making it more porous. The post-test forensic analysis revealed that the washed fraction comprised fine and medium sand particles smaller than the controlling constriction sizes of coarse fractions. During internal instability, the coarse particles remain intact (i.e., stable), while the effluent accompanies the fine particles from the pore spaces without causing reductions in specimen volume. The specimen boundary conditions do not influence the process of erosion in internally unstable soils, where the interparticle friction plays a more significant role.

Fig. 12b shows that an internally stable soil exhibits heave development at $i_{c r, a} \geq i_{c r, t}$ that may or may not be accompanied by some limited erosion, depending upon the soil type; e.g., fully compacted B1 and B2 showed composite heave-piping failures. At the critical onset of heave, an internally stable specimen is lifted like a rigid soil column by the hydraulic forces, resulting in occasional volume changes. The seepage and buoyant forces neutralize the effective stresses and boundary (skin) friction, thereby allowing the whole specimen to move as an entity. No or very limited erosion (under dynamic conditions) with unaltered post-test PSD curves indicates that the interparticle arrangement remains intact during the occurrence of heave, where boundary friction from cell walls may play an important role.

\section{Practical Implications}

The technique proposed here may be used for a prompt evaluation of the internal instability potential of granular filters, which function under severe cyclic loading conditions such as those induced by high-speed trains. As demonstrated, the proposed CSDbased approach only requires the PSD of filter to be examined to assess the potential of instability, while assuming $R_{d}=0$ under cyclic loading at $f>5 \mathrm{~Hz}$. This technique may easily be coupled with any of the existing filter design criteria including the Natural
FIG. 12

Illustrations of the mechanisms of seepage induced failures in (a) internally unstable and (b) stable granular soils.
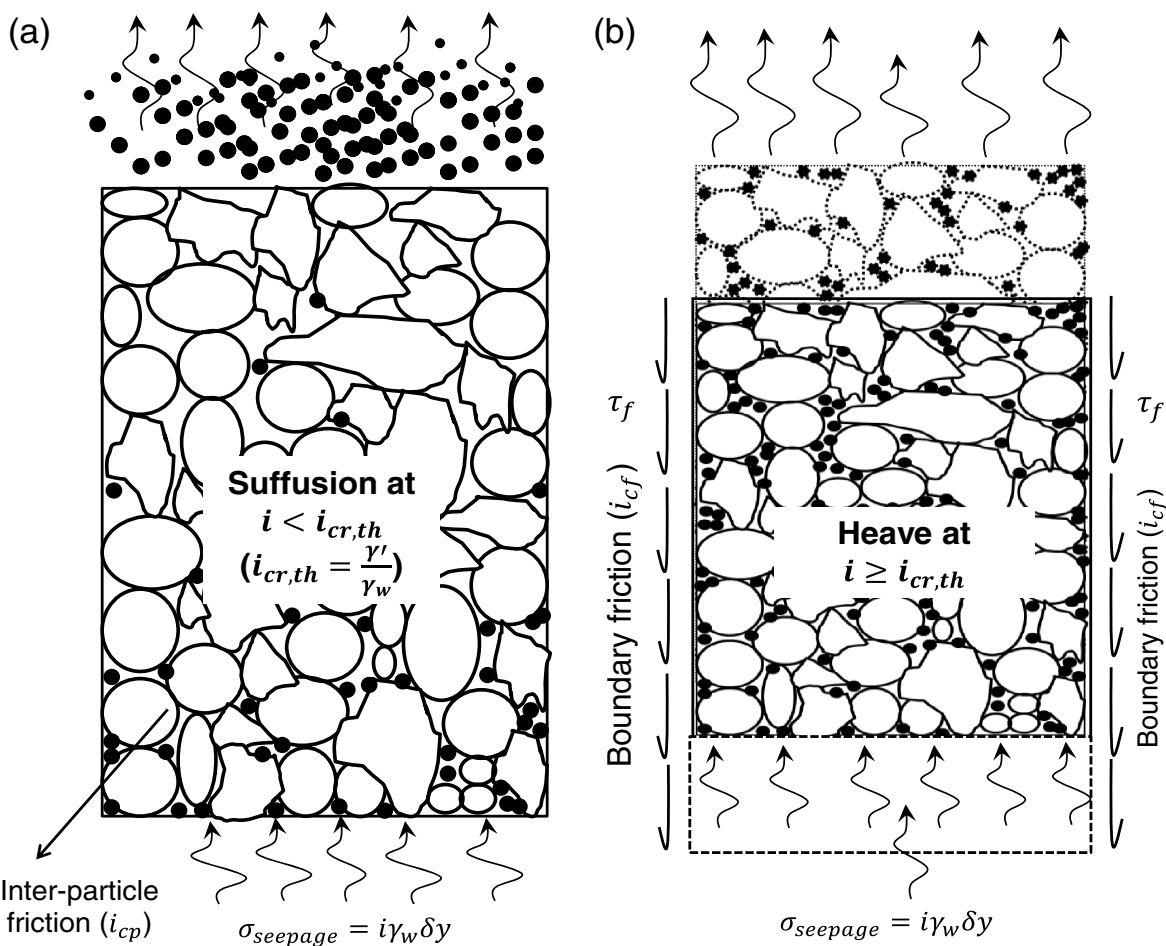
Resources and Conservation Service (1994), International Commission on Large Dams (ICOLD 1994), Indraratna, Raut, and Khabbaz (2007), Raut and Indraratna (2008), and Trani and Indraratna (2010) for enhanced reliability. For example, the procedure for filter design requires one to examine the instability potential of base and filter soils as a first step. Natural subgrades consisting of broadly and gap-graded dispersive soils are likely to suffer from internal erosion, which may become excessive under cyclic loading, as shown by the current soil G2. A timely assessment may allow for the possible regrading of the base before choosing a suitable protecting filter.

\section{Concluding Remarks}

Based on the principal findings of this study, the following conclusions have been drawn:

- Broadly and gap-graded soils $\left(C_{u}>10\right.$ and $\left.G_{r}>5\right)$ exhibit a greater tendency to suffer from instability. These soils exhibit suffusion at relatively smaller hydraulic gradients $\left(i_{c r}<1\right)$ compared to the uniform and well-graded soils $\left(C_{u}<10\right)$, which fail in heave at $i_{c r} \approx 1$.

- The risk of internal instability is higher in loose soils that can be markedly reduced by increasing their level of compaction.

- The existing PSD-based criteria showed limited success in correctly assessing the internal stability of soils under static conditions, whereas the CSD-based approach of Indraratna, Israr, and Rujikiatkamjorn (2015) showed $100 \%$ success. Not surprisingly, none of the existing criteria could successfully characterize the internal stability of soils under cyclic loading.

- Cyclic loading triggers suffusion in soils that becomes increasingly premature at higher frequencies $(f \geq 5 \mathrm{~Hz})$. Nevertheless, the increase in static loading magnitude increases the internal stability of soils by reducing erosion and escalating the magnitude of $i_{c r}$ for instability.

- By assuming $R_{d}=0$ to compensate for the effects of cyclic loading, the CSD-based criterion could accurately predict the internal instability potential of current soils.

- Soils with $C_{u}<10$ possess relatively higher internal stability under cyclic conditions; e.g., the currently tested uniform medium sands and fine gravels showed enhanced stability under high frequency cyclic loading. Therefore, the choice of filters may be limited to soils with $C_{u}<10$ to ensure stability and longevity under unfavorable hydraulic conditions, e.g., in railway substructures and embankment dams in earthquake-prone regions.

In this study, a single magnitude of heavy-haul dynamic load was simulated, i.e., $\sigma_{\text {min }}^{\prime}=30 \mathrm{kPa}, \sigma_{\text {max }}^{\prime}=70 \mathrm{kPa}$, and $\sigma_{\text {mean }}^{\prime}=$ $50 \mathrm{kPa}$ and the frequency was varied between 0 and $30 \mathrm{~Hz}$. Therefore, caution is warranted when extrapolating these results and the proposed revision to soils subjected to considerably different conditions. Although the existing CSD criterion of Indraratna, Israr, and Rujikiatkamjorn (2015) may still be used at lower frequencies with caution, the proposed revision would be more appealing to the practitioners at higher cyclic loading frequencies $(f \geq 5 \mathrm{~Hz})$.

\section{ACKNOWLEDGMENTS}

Faculty Development Program and International Post-Graduate Tuition Award scholarships from the University of Engineering and Technology Lahore (Pakistan) and the University of Wollongong (Australia) are gratefully appreciated by the first author.

\section{References}

ASTM D1557-00, 2000, Standard Test Methods for Laboratory Compaction Characteristics of Soil Using Modified Effort $\left(56,000 \mathrm{ft}-\mathrm{lbf} / \mathrm{ft}^{3}\left(2,700 \mathrm{kN}-\mathrm{m} / \mathrm{m}^{3}\right)\right)$ (Superseded), ASTM International, West Conshohocken, PA, https://www.astm. org/Standards/D1557

ASTM D4253-06, 2006, Standard Test Methods for Maximum Index Density and Unit Weight of Soils Using a Vibratory Table (Superseded), ASTM International, West Conshohocken, PA, https://www.astm.org/Standards/D4253

ASTM D4254-00, 2006, Standard Test Methods for Minimum Index Density and Unit Weight of Soils and Calculation of Relative Density (Superseded), ASTM International, West Conshohocken, PA, https://www.astm.org/Standards/D4254

ASTM D5101-01, 2001, Standard Test Method for Measuring the Soil-Geotextile System Clogging Potential by the Gradient Ratio, ASTM International, West Conshohocken, PA, https://www.astm.org/Standards/D5101

ASTM D698-07, 2007, Standard Test Methods for Laboratory Compaction Characteristics of Soil Using Standard Effort (12 $400 \mathrm{ft}$-lbf/ft $\left.\mathrm{ft}^{3}\left(600 \mathrm{kN}-\mathrm{m} / \mathrm{m}^{3}\right)\right)$ (Superseded), ASTM International, West Conshohocken, PA, https://www.astm. org/Standards/D698

Chapuis, R. P., 1992, "Similarity of Internal Stability Criteria for Granular Soils,” Can. Geotech. J., Vol. 29, No. 4, pp. 711-713, https://doi.org/10.1139/t92-078

Christie, D., 2007, "Bulli Field Trial: Vertical and Lateral Pressure Measurement," presented at the Rail CRC Seminar, Wollongong, Australia, University of Wollongong, Wollongong, Australia.

Das, B. M., 2008, Advanced Soil Mechanics, Taylor \& Francis, London, England, pp. 28-46.

Fannin, R. and Moffat, R., 2006, "Observations on Internal Stability of Cohesionless Soils," Géotechnique, Vol. 56, No. 7, pp. 497-500, https://doi.org/10.1680/geot.2006.56.7.497

Fourie, A. B., Copeland, A. M., and Barrett, A. J., 1994 "Optimization of the As-Placed Properties of Hydraulic Backfill," J. South Afr. Inst. Min. Met., Vol. 94, No. 8, pp. 199-210.

Head, K. H., 1982, Manual of Soil Laboratory Testing, Permeability, Shear Strength and Compressibility Tests (Volume 2), Pentech Press, London, England, pp. 120-133.

ICOLD (International Commission on Large Dams), 1994, Embankment dams-Filters and drains, Bulletin, No. 95, ICOLD, Paris, France. 
Indraratna, B., Israr, J., and Rujikiatkamjorn, C., 2015, "Geometrical Method for Evaluating the Internal Instability of Granular Filters Based on Constriction Size Distribution," J. Geotech. Geoenviron. Eng., Vol. 141, No. 10, 04015045, https://doi.org/10.1061/(ASCE)GT.1943-5606.0001343

Indraratna, B., Israr, J., and Rujikiatkamjorn, C., 2016, “Closure to 'Geometrical Method for Evaluating the Internal Instability of Granular Filters Based on Constriction Size Distribution' by B. Indraratna, J. Israr, and C. Rujikiatkamjorn, The Technical Paper Was Published in the Journal of Geotechnical and Geoenvironmental Engineering, Vol. 141, No. 10 [DOI: https://doi.org/10.1061/(ASCE)GT.1943-5606. 0001343]," Journal of Geotechnical and Geoenvironmental Engineering, Vol. 142, No. 9, https://doi.org/10.1061/(ASCE) GT.1943-5606.0001537

Indraratna, B., Raut, A. K., and Khabbaz, H., 2007, "ConstrictionBased Retention Criterion for Granular Filter Design," J. Geotech. Geoenviron. Eng., Vol. 133, No. 3, pp. 266-276, https://doi.org/10.1061/(ASCE)1090-0241(2007)133:3(266)

Israr, J., 2016, "Internal Instability of Granular Filters under Cyclic Loading," Ph.D. thesis, University of Wollongong, Wollongong, Australia.

Israr, J. and Indraratna, B., 2017, "Internal Stability of Granular Filters under Static and Cyclic Loading," J. Geotech. Geoenviron. Eng., Vol. 143, No. 6, 04017012, https://doi. org/10.1061/(ASCE)GT.1943-5606.0001661

Israr, J., Indraratna, B., and Rujikiatkamjorn, C., 2016, "Laboratory Investigation of the Seepage Induced Response of Granular Soils Under Static and Cyclic Loading," Geotech. Test. J., Vol. 39, No. 5, pp. 795-812, https://doi. org/10.1520/GTJ20150288

Kenney, T. C., Chahal, R., Chiu, E., Ofoegbu, G. I., Omange, G. N., and Ume, C. A., 1985, "Controlling Constriction Sizes of Granular Filters," Can. Geotech. J., Vol. 22, No. 1, pp. 3243, https://doi.org/10.1139/t85-005

Kenney, T. C. and Lau, D., 1985, "Internal Stability of Granular Filters," Can. Geotech. J., Vol. 22, No. 2, pp. 215-225, https:// doi.org/10.1139/t85-029

Kézdi, A., 1979, Soil Physics, Volume 25, Elsevier Scientific, Amsterdam, The Netherlands.

Li, M. and Fannin, R. J., 2008, "Comparison of Two Criteria for Internal Stability of Granular Soil," Can. Geotech. J., Vol. 45, No. 9, pp. 1303-1309, https://doi.org/10.1139/T08-046

Locke, M., Indraratna, B., and Adikari, G., 2001, "TimeDependent Particle Transport through Granular Filters," J. Geotech. Geoenviron. Eng., Vol. 127, No. 6, pp. 521-529, https://doi.org/10.1061/(ASCE)1090-0241(2001)127:6(521)

Moffat, R. and Fannin, R. J., 2006, "A Large Permeameter for Study of Internal Stability in Cohesionless Soils," Geotech. Test. J., Vol. 29, No. 4, pp. 273-279, https://doi.org/10. 1520/GTJ100021
Moffat, R. and Fannin, R. J., 2011, “A Hydromechanical Relation Governing the Internal Stability of Cohesionless Soil," Can. Geotech. J., Vol. 48, No. 3, pp. 413-424, https://doi.org/10. 1139/T10-070

Moffat, R., Fannin, R. J., and Garner, S. J., 2011, "Spatial and Temporal Progression of Internal Erosion in Cohesionless Soil,” Can. Geotech. J., Vol. 48, No. 3, pp. 399-412, https:// doi.org/10.1139/T10-071

Natural Resources Conservation Services, 1994, "Gradation Design of Sand and Gravel Filters," National Engineering Handbook, Chap. 26, Part 633, USDA.

Raut, A. K. and Indraratna, B., 2008, "Further Advancement in Filtration Criteria through Constriction-Based Techniques," J. Geotech. Geoenviron. Eng., Vol. 134, No. 6, pp. 883-887, https://doi.org/10.1061/(ASCE)1090-0241(2008)134:6(883)

Reddi, L. N., 2003, Seepage in Soils: Principles and Applications, John Wiley \& Sons, Hoboken, NJ, pp. 196-214.

Sherard, J. L., 1979, "Sinkholes in Dams of Coarse Broadly Graded Soils," presented at the 13th ICOLD Congress, New Delhi, India, International Commission on Large Dams, Paris, France.

Skempton, A. W. and Brogan, J. M., 1994, "Experiments on Piping in Sandy Gravels," Géotechnique, Vol. 44, No. 3, pp. 449-460, https://doi.org/10.1680/geot.1994.44.3.449

Smith, J. L. and Bhatia, S. K., 2010, "Minimizing Soil Erosion with Geosynthetic Rolled Erosion Control Products," Geo-StrataGeo Inst., Vol. 14, No. 4, pp. 50-53.

Terzaghi, K., 1939, "Soil Mechanics-A New Chapter in Engineering Science," J. Inst. Civ. Eng., Vol. 12, No. 7, pp. 106-141, https://doi.org/10.1680/ijoti.1939.14534

Trani, L. D. O. and Indraratna, B., 2010, "Assessment of Subballast Filtration under Cyclic Loading," J. Geotech. Geoenviron. Eng., Vol. 136, No. 11, pp. 1519-1528, https:// doi.org/10.1061/(ASCE)GT.1943-5606.0000384

USACE, 1953, "Investigation of Filter Requirements for Underdrains," Tech. Memo. No. 3-360, U.S. Waterways Experiment Station, Vicksburg, MS.

Xiao, M., Reddi, L. N., and Steinberg, S., 2006, "Effect of Vibrations on Pore Fluid Distribution in Porous Media," Transp. Porous Med., Vol. 62, No. 2, pp. 187-204, https:// doi.org/10.1007/s11242-005-1734-1

Xiao, M. and Shwiyhat, N., 2012, "Experimental Investigation of the Effects of Suffusion on Physical and Geomechanic Characteristics of Sandy Soils," Geotech. Test. J., Vol. 35, No. 6, 890-900, https:// doi.org/10.1520/GTJ104594

Zou, Y., Chen, Q., Chen, X., and Cui, P., 2013, "Discrete Numerical Modelling of Particle Transport in Granular Filters," Comput. Geotech., Vol. 47, pp. 48-56, https://doi. org/10.1016/j.compgeo.2012.06.002 